\title{
PRINSIP-PRINSIP KESANTUNAN BERBAHASA DALAM INTERAKSI ANTARA SESAMA PENUTUR AMBON
}

\section{THE POLITENESS PRINCIPLES ON LANGUAGE INTERACTION AMONG AMBONESE SPEAKERS}

\author{
Michele Hitijahubessy \\ Fakultas Ilmu Budaya, Universitas Brawijaya \\ Ponsel: 085254055445 \\ Pos-el: michele.hiti@gmail.com
}

\begin{abstract}
Abstrak
Kesantunan berbahasa berperan dalam membangun hubungan baik dengan seseorang karena kesantunan berbahasa dapat membuat interaksi yang dilakukan berjalan lancar, efektif, dan tidak mengancam muka. Melihat fenomena tersebut peneliti melakukan penelitian dengan tujuan untuk mendeskripsikan tipe prinsip berbahasa dalam interaksi penutur Ambon. Penelitian ini menggunakan metode kualitatif dengan pendekatan pragmatik. Kemudian dalam pengumpulan data, peneliti menggunakan tiga teknik yaitu: teknik simak bebas libat cakap, teknik rekam, dan teknik catat. Setelah data diperoleh, kemudian peneliti mengklasifikasikan data dan menganalisis menggunakan konsep prinsip-prinsip kesantunan dari Leech (1983) dan strategi kesantunan dari Brown dan Lavison (1987). Hasil dari penelitian ini peneliti menemukan bahwa penutur Ambon dalam berinteraksi sehari-hari menggunakan keenam maksim yaitu maksim kebijaksanaan, maksim kedermawaan, maksim pujian, maksim kerendahan hati, maksim kesepakatan, dan maksim simpati. Serta strategi kesantunan yang dipakai adalah strategi kesantunan positif dan strategi kesantunan negatif. Hal ini agar interaksi yang dilakukan dapat berjalan lancar, menjaga hubungan baik, dan efektif.
\end{abstract}

Kata kunci: prinsip-prinsip kesantunan, strategi kesantunan, penutur Ambon

\begin{abstract}
Language politeness plays a role in building good relations with someone because language politeness can make the interaction run smoothly, effectively, and not threatening face. Seeing this phenomenon researchers conducted research with the aim of describing the type of language principle in the interaction of Ambonese speakers. This study used qualitative methods with a pragmatic approach. In data collection, this study used three techniques, free speech techniques, recording techniques, and note-taking techniques. After the data was obtained, then the researcher clasified the data and then analyzed using the concepts of politeness principles from Leech (1983) and politeness strategies from Brown and Lavison (1987). The results of this study researchers found that Ambonese speakers interact daily using the six maxims: tact maxim, generosity maxim, approbation maxim, modesty maxim, agreement maxim, and sympathy maxim. Politeness strategies used are positive politeness strategies and negative politeness strategies. This is so that the interaction can run smoothly, maintain good relations, and be effective.
\end{abstract}

Keywords: politeness principles, politeness strategy, Ambonese speaker

1. Pendahuluan

Dalam kehidupan sehari-hari, penting untuk membangun hubungan baik dengan orangorang disekitar kita, baik yang dikenal maupun tidak dikenal. Salah satu cara yang dapat dilakukan adalah dengan menjaga kesantunan kita dalam berbahasa. Kesantunan berbahasa memegang peran penting dalam membangun hubungan yang baik dan hubungan yang saling menghormati antara penutur dan lawan 
tuturnya. Kesantunan berbahasa merupakan salah satu topik yang menarik dibicarakan dan diteliti karena berkaitan erat dengan kehidupan kita sehari-hari.

Mislikhah (2014:287) mendefinisikan kesantunan adalah "tata cara, adat, atau kebiasaan yang berlaku dalam masyarakat". Lebih lanjut Mislikhah melihat kesantunan berbahasa tercermin dari tatacara seseorang dalam berkomunikasi lewat tanda verbal. Ketika berbahasa kita tidak bisa dengan seenaknya mengemukakan pendapat kita tanpa melihat norma-norma kesantunan atau normanorma budaya yang berlaku di masyarakat yang menjadi tempat hidup atau tempat lokasi pemakaian bahasa itu. (Mislikhah, 2014). Ide atau pemikiran yang kita sampaikan tidak hanya sekedar kita sampaikan tetapi harus tunduk pada norma-norma budaya yang berlaku (Siminto, 2016). Karena bahasa yang digunakan dapat mencerminkan budaya suatu masyarakat (Mauruf, 2016). Dari cara kita bertutur, orang dapat melihat bagaimana budaya kita. Dari kecil, kesantunan sudah diterapkan oleh orang tua kepada anakanaknya atau orang yang lebih tua kepada orang yang lebih muda. Hadiwijaya dan Yahmun (2017) menegaskan bahwa dalam bertutur, penting untuk memilih kata yang akan kita gunakan serta memperhatikan lokasi, waktu, lawan bicara, dan tujuan kita berbicara. Tentu saja dalam menjaga kesantunan kita mempunyai tujuan, Nurjamili (2015) menjelaskan bahwa tujuan kesantunan berbahasa adalah untuk membuat suasana berinteraksi menyenangkan, tidak mengancam muka dan efektif.

Karena kesantunan berbahasa sangat berkaitan erat dengan kehidupan kita seharihari, tidak heran kalau kesantunan berbahasa sangat menarik untuk diteliti oleh para peneliti khususnya para peneliti pada ilmu linguistik. Simatupang (2017) dalam penelitiannya dengan judul "Prinsip-Prinsip Kesopanan dalam Ujaran Mahasiswa Semester 6 Fakultas Ilmu Budaya UNSRAT: Sebuah Analisis Pragmatik" menemukan enam puluh tujuh ujaran kesopanan yang dianalisis berdasarkan teori Leech dan terdapat enam tipe prinsip kesopanan berupa maksim, yaitu maksim kebijaksanaan, maksim dermawan, maksim pujian, maksim kerendahan hati, maksim kesepakatan, dan maksim simpati.

Selain itu, ada pula penelitian yang dilakukan oleh Eka (2015) yang berjudul "Kesantunan Pengungkapan Kalimat Perintah dalam Perkuliahan Bahasa Indonesia Mahasiswa Sekolah Tinggi Agama Islam (STAI)". Penelitian tersebut menemukan bahwa dalam melakukan diskusi selama perkuliahan Bahasa Indonesia, mahasiswa Sultan Abdulrahman Tanjungpinang Riau terpusat pada orang yang memerintah atau si penutur, sedangkan jenis kalimat imperatif atau ilokusi langsung merupakan tuturan pengungkapan perintah yang kurang sopan dan merugikan petutur. Sementara itu, jenis kalimat deklaratif dan interogatif atau ilokusi tidak langsung, yaitu kalimat perintah yang tidak secara langsung merupakan tuturan yang lebih sopan dan tidak merugikan petutur.

Budiwati (2017) dalam penelitiannya yang juga meneliti kesantunan dengan judul "Kesantunan Berbahasa Mahasiswa dalam Berinteraksi dengan Dosen di Universitas Ahmad Dahlan: Analisis Pragmatik". Dalam penelitiaanya, ia menemukan bahwa percakapan antara Mahasiswa UAD dan dosen melalui media sosial WhatsApp maupun Line Chat yang cenderung berbentuk informal dan terkesan santai. Hal ini terkait dengan umur dosen yang masih muda dan membuat mahasiswa lebih santai dalam berkomunikasi. Penelitian itu juga menemukan bahwa kesantunan berbahasa mahasiswa adalah muka positif dan muka negatif. Terdapat juga pematuhan dan penyimpangan terhadap beberapa maksim, yaitu maksim kebijaksanaan, maksim kedermawanan, maksim penerimaan, maksim persetujuan serta maksim simpati. Selain itu, fungsi-fungsi berbahasa, seperti fungsi representatif, fungsi direktif, fungsi ekspresif, dan fungsi komisif.

Dari ketiga penelitian terdahulu tersebut, didapati bahwa ketiga lokasi penelitian lebih banyak di lingkungan kampus dan objek penelitian tersebut sama, yaitu antara mahasiswa dan mahasiswa serta mahasiswa dan dosen. Sementara itu, penelitian ini dilakukan di lingkungan rumah, tepatnya di 
sebuah rumah kontrakan di Malang. Mayoritas penghuninya merupakan penutur Ambon dan menggunakan bahasa Ambon dalam percakapan mereka sehari-hari. Penelitian ini menarik dilakukan untuk melihat fenomena kesantunan berbahasa yang terjadi di antara penutur Ambon. Patut diketahui pula bahwa umur objek penelitian tidak terpaut jauh antara satu dan yang lainnya. Penelitian ini juga dilakukan karena kesantunan berbahasa merupakan hal yang penting dalam membangun komunikasi dengan orang lain di era globalisasi. Berdasarkan uraian latar belakang tersebut, masalah yang akan diangkat pada penelitian ini ialah (1) bagaimana tipe prinsip kesantunan berbahasa dalam interaksi antara penutur Ambon? dan (2) strategi kesopanan apa sajakah yang digunakan oleh penutur Ambon? Penelitian ini dilakukan dengan tujuan untuk mendeskripsikan tipe prinsip berbahasa dan strategi kesopanan dalam interaksi penutur Ambon.

\section{Metode}

Penelitian ini menggunakan metode kualitatif. Metode penelitian ini merupakan penelitian yang menghasilkan data deskriptif, data yang dikumpulkan berupa kata-kata, baik secara verbal maupun nonverbal dari orang atau perilaku yang dapat diamati. Pendekatan yang digunakan pada penelitian ini adalah pendekatan pragmatik. Pendekatan ini dipilih karena sesuai dengan tujuan dari penelitian ini, dimana peneliti berusaha mendeskripsikan tipe prinsip kesantunan berbahasa dalam interaksi antara sesama penutur Ambon.

Penelitian ini dilakukan pada lingkungan penutur Ambon yang berada di sebuah rumah kontrakan. Penghuni rumah kontrakan itu mayoritas penutur asli Ambon yang berada di Malang. Mereka memiliki umur yang tidak terpaut jauh, antara 22 sampai 24 tahun. Data diambil selama empat hari, tepatnya dari tanggal 13 Mei 2018 sampai tanggal 17 Mei 2018. Jenis penelitian ini adalah jenis penelitian lapangan, peneliti terlibat langsung dalam mengikuti, merekam dan mencatat ujaran-ujaran yang dihasilkan antarpenutur Ambon dalam melakukan aktivitas sehari-hari yang merupakan sumber data.
Dalam pengumpulan data, penelitian ini menggunakan tiga teknik. Pertama, teknik simak bebas libat cakap, peneliti tidak terlibat langsung pada saat penuturan bahasa yang sedang diteliti. Peneliti hanya menyimak percakapan yang sedang terjadi. Kedua, teknik rekam, percakapan dilakukan secara spontan maka peneliti menggunakan alat rekam berupa sebuah telepon genggam untuk merekam percakapan yang terjadi. Setelah itu, rekaman tersebut didengar dan dicatat. Ketiga, teknik catat, peneliti mencatat ujaran-ujaran dari percakapan yang terjadi.

Setelah data diperoleh, kemudian akan diklasifikasi dan kemudian akan dianalisis menggunakan konsep prinsip-prinsip kesantunan dari Leech (1983) dan strategi kesantunan dari Brown dan Levison (1987). Terakhir, peneliti membuat kesimpulan dari hasil yang diperoleh.

\section{Hasil dan Pembahasan}

Hasil penelitian ini diperoleh dari pengamatan, perekaman, dan pencatatan terhadap informan penelitian. Hasil penelitian diperoleh dari data yang telah diklasifikasikan dan dianalisis oleh peneliti. Nama penutur tidak disertakan dalam data rekaman percakapan. Peneliti memberikan kode peutur (A) dan mitra tutur (B) untuk data tersebut.

\subsection{Tipe-tipe prinsip kesantunan penutur Ambon}

Dalam tahap klasifikasi dan analisis tipe prinsip kesopanan dalam interaksi penutur Ambon, peneliti menemukan enam maksim yang digunakan, yaitu maksim kebijaksanaan, maksim dermawan, maksim pujian, maksim kerendahan hati, maksim kesepakatan, dan maksim simpati.

\subsubsection{Maksim Kebijaksanaan}

Maksim ini bertujuan untuk meminimalkan kerugian pada orang lain dan memaksimalkan kerugian pada diri sendiri.

Data

Situasi: Percakapan ini terjadi ketika penutur (A) dan mitra tutur (B) selesai makan dan penutur (A) menawarkan diri untuk mencuci piring. 
A: Kas tinggal sa, nanti beta cuci akang piring tu, nanti se lalah.

'Tinggalkan saja nanti saya yang akan mencuci piringnya, nanti kau lelah'

B: Seng papa to e se yang cuci?

'Tidak apa-apa kan kau yang mencuci?'

A: Seng papa, kaya orang saja.

'Tidak apa-apa, seperti tidak kenal saja'

Analisis: Berdasarkan ukuran prinsip kesantunan menurut Leech dalam percakapan tersebut termasuk santun karena sesuai dan mematuhi maksim kebijaksanaan, penutur (A) meminimalkan kerugian pada orang lain dan memaksimalkan kerugian pada dirinya sendiri. Hal ini dapat terlihat dari ujaran "nanti beta cuci akang piring tu". Ujaran tersebut penutur (A) meminimalkan kekerugian pada mitra tutur yang akan lelah kalau mencuci piring dengan mencuci piring tersebut dan memaksimalkan kerugian kepada dirinya yang akan mencuci piring.

\subsubsection{Maksim Dermawan}

Maksim ini bertujuan meminimalkan keuntungan pada diri sendiri dan maksimalkan kerugian pada diri sendiri.

Data

Situasi: Percakapan ini terjadi di dapur, ketika penutur (A) mengajak mitra tutur (B) untuk memakan martabak yang baru di beli oleh penutur (A).

\section{A: Beta baru bali martabak di kamar tu, maso la mabel sa. \\ 'Saya baru membeli martabak dan sekarang di kamar, masuk lalu ambil saja' \\ B: Dangke \\ 'Terima kasih'}

Analisis: Berdasarkan ukuran prinsip kesantunan menurut Leech dalam percakapan tersebut termasuk santun karena sesuai dan mematuhi maksim dermawan. Penutur (A) meminimalkan keuntungan pada diri sendiri dan maksimalkan kerugian pada diri sendiri, hal ini dapat terlihat dari ujaran "maso la mabel sa". Penutur mempersilakan mitra tutur (B) masuk ke dalam kamarnya untuk mengambil martabak.

\subsubsection{Maksim Pujian}

Maksim ini bertujuan meminimalkan pujian diri sendiri dan maksimalkan pujian untuk orang lain.

Data

Situasi: Percakapan ini terjadi ketika mitra tutur (B) baru membeli baju.

\author{
A: Se pung baju baru tu akang (baju) \\ bagus. \\ 'Baju barumu bagus' \\ B: Ka? Dangke. \\ 'Benarkah? Terima kasih'
}

Analisis: Berdasarkan ukuran prinsip kesantunan menurut Leech dalam percakapan itu termasuk santun karena sesuai dan mematuhi maksim pujian. Penutur (A) meminimalkan memuji diri sendiri dan maksimalkan pujian untuk orang lain, terlihat dari ujaran "Se pung baju baru tu akang (baju) bagus". Penutur memuji baju mitra tutur yang baru.

\subsubsection{Maksim Kerendahan Hati}

Maksim ini bertujuan meminimalkan pujian pada diri sendiri dan memaksimalkan kritikan pada diri sendiri.

Data

Situasi: Percakapan ini terjadi ketika penutur (A) dan mitra tutur (B) berada di ruang tamu dan penutur (A) ingin agar mitra tutur (B) memainkan gitar.

A: Ini gitar, maeng akang (gitar) kan se su jago tu.

'Ini gitar, coba mainkan kan kau sudah jago memainkannya'

B: Beta maeng sa ada tarbae mo.

'saya bermain masih belum bagus'

Analisis: Berdasarkan ukuran prinsip kesantunan menurut Leech dalam percakapan itu termasuk satun karena sesuai dan mematuhi maksim kerendahan hati, dalam hal ini terlihat penggunaan ujaran "Beta maeng sa ada tarbae mo" oleh mitra tutur. Dimana mitra tutur meminimalkan pujian pada diri sendiri, walaupun mahir memainkan gitar tetapi mitra tutur memaksimalkan kritikan pada diri sendiri dengan merendahkan dirinya sendiri. 


\subsubsection{Maksim Kesepakatan}

Maksim ini bertujuan meminimalkan ketidaksepakatan antara diri sendiri dengan orang lain dan memaksimalkan kesepakatan antara diri sendiri dengan orang lain.

Data

Situasi: Percakapan ini terjadi ketika penutur (A) dan mitra tutur (B) membeli Es Kepal Milo di depan kompleks perumahan.

\section{A: Es Kepal Milo yang katong bali di muka ni akang enak to? \\ 'Es Kepal Milo yang kita beli di depang kompleks ini enak kan?' \\ B: Iyo, batul enak. \\ 'Iya benar enak'}

Analisis: Berdasarkan ukuran prinsip kesantunan menurut Leech dalam percakapan tersebut termasuk santun karena sesuai dan mematuhi maksim kesepakatan, mitra tutur (B) memaksimalkan kesepakatan antara diri sendiri dengan penutur (A) mengenai rasa Es Kepal Milo yang dibeli oleh mereka, terlihat dari ujaran "Iyo, batul enak".

\subsubsection{Maksim Simpati}

Maksim ini meminimalkan antipati antara diri sendiri dengan orang lain dan memaksimalkan simpati antara diri sendiri dengan orang lain.

Data

Situasi: Percakapan ini terjadi ketika penutur (A) memperlihatkan lututnya yang luka karena kecelakaan ketika mengendarai motornya kepada mitra tutur (B).

A: Beta to pung lutu akang luka gara-gara jatoh kamareng.

'Lutut saya luka karena jatuh kemarin'

B: Ka? Kasiang e.

'Benarkah? Kasihan sekali'

Analisis: Berdasarkan ukuran prinsip kesantunan menurut Leech dalam percakapan diatas termasuk santun karena sesuai dan mematuhi maksim simpati, hal ini terlihat dari ujaran "Kasiang e". Mitra tutur (B) dalam kalimat tersebut menunjukan rasa simpatinya kepada penutur yang terluka karena kecelakaan.

\subsection{Strategi Kesantunan Penutur Ambon}

Dalam tahap klasifikasi dan analisis strategi kesantunan penutur Ambon, peneliti menggunakan strategi kesantunan dari Brown dan Levison (1987). Peneliti menemukan dua strategi yang digunakan, yaitu strategi kesantunan positif dan strategi kesantunan negatif.

\subsubsection{Strategi Kesantunan Positif}

Strategi ini digunakan oleh penutur agar dipandang baik serta dianggap sebagai teman atau orang kepercayaan oleh mitra tutur.

Data

Situasi: Penutur (A) ingin meminjam sepatu untuk pergi bermail bola.

\section{A: Bu, bisa pinjang sapatu futsal ni kah? 'Bung, bisakah meminjam sepatu futsal ini?' B: Ambel saja! \\ 'Ambil saja!'}

Analisis: Penutur memanggil mitra tutur dengan panggilan $b u$ yang biasa digunakan kepada lelaki supaya terkesan lebih sopan dan dekat. Penutur menggunakannya agar terjadi kedekatan antara mereka.

\subsubsection{Strategi Kesantunan Negatif}

Penutur menggunakan strategi ini agar tidak membuat tuturannya terkesan memaksa dengan cara memberikan pilihan kepada mitra tuturnya.

Data

Situasi: Penutur (A) memberikan pilihan kepada mitra tutur (B) agar dapat memilih martabak mana yang lebih disukai oleh mitra tutur.

A: Kak, mau yang mana? Maartabak biasa ka spesial?

'Kak mau yang mana? Martabak biasa atau yang spesial?'

B: Yang mana sa

'Yang mana saja'

Analisis: Penutur memberikan pilihan kepada mitra tutur memilih martabak mana yang mau dimakan. Hal ini agar penutur terlihat lebih sopan kepada mitra tutur yang lebih tua darinya. 


\section{Simpulan}

Berdasarkan penelitian yang dilakukan oleh peneliti pada penutur Ambon, peneliti dapat menyimpulkan bahwa kesopanan masih dianggap penting di era globalisasi. Hal ini adalah upaya untuk memperlacar komunikasi dan menjaga hubungan baik dengan orang lain. Penutur Ambon dalam hal ini juga melakukan hal yang sama, dalam memperlancar hubungan dan menjaga hubungan baik mereka. Walaupun jarak usia mereka tidak terpaut jauh, mereka tetap menerapkan prinsip-prinsip kesantunan berbahasa dan strategi kesantunan sewaktu berinteraksi dalam kehidupan sehari-hari.

Sayangnya penelitian ini hanya dilakukan dalam waktu singkat sehingga peneliti tidak dapat melihat adanya penyimpangan kesatunan yang terjadi oleh penutur Ambon, untuk itu peneliti menyarankan kepada peneliti selanjutnya untuk meneliti hal tersebut. Dalam penelitian ini juga peneliti menyarankan untuk peneliti selanjutnya agar dapat melihat hubungan antara kesantunan dengan usia sesorang.

\section{Daftar Pustaka}

Brown, P., \& Levison, S. C. (1987). Politeness: Some Universals in Language Usage. 2nd ed. Cambridge: Cambridge University Press.

Budiwati, T. R. (2017). Kesantunan Berbahasa Mahasiwa dalam Berinteraksi dengan Dosen di Universitas Ahmad Dahlan: Analisis Pragmatil. The $5^{\text {th }}$ URECOL Proceeding.

Eka, R. K. (2015). Kesantunan Pengungkapan Bahasa Indonesia Mahasiswa Sekolah Tinggi Agama Islam (STAI). Dialetika: Jurnal bahasa, satra, dan pendidikan bahasa dan satra Indonesia, 2 (1), hal. 34- 49 .

Hadiwijaya, M \& Yahmun. (2017). Kesantunan Berbahasa dalam Interaksi antara Dosen dan Mahasiswa Multikultural. Didaktika, Vol. 23, No. 2.

Leech, G. (1983). "The Principle of Pragmatics". London: Cambridge.
Maufur, S. (2016). Penerapan Prinsip Kerja Sama dan Prinsip Sopan Santun Berbahasa di Kalangan Masyarakat Kampung Pesisir Kota Cirebon. Al Ibtida. Vol. 3. No. 1.

Mislikhah, S. (2014). Kesantunan Berbahasa. Ar-Raniry: International Journal of Islamic studies. Vol.1. No.2.

Nurjamily, Wa Ode. (2015). Kesantunan Berbahasa Indonesia dalam Lingkungan Keluarga (kajian Sosiopragmatik). Journal Humanika. No. 15. Vol. 3.

Simatupang, M. (2017). Prinsip-Prinsip Kesopanan dalam Ujaran Mahasiswa Semester 6 Fakultas Ilmu Budaya UNSRAT: Sebuah Analisis Pragmatik.

Sisminto, S. (2016). Pelaksanaan Prinsip kesantunan Melalui Short Message Service. Seminar Nasional PRASASTI (Prakmatik: Sastra dan Linguistik). 